\title{
Midurethral sling complications
}

\section{Sender Herschorn, MD}

Division of Urology University of Toronto, Sunnybrook Health Sciences Centre, Toronto, ON, Canada
Cite as: Can Urol Assoc J 2017;11 (6Suppl2):S141-2. http://dx.doi.org/10.5489/cuaj.4692

See related article on page $S 135$.

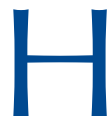

engel et al have carefully and extensively reviewed the intraoperative and early and late postoperative complications that can arise after insertion of a midurethral sling (MUS) for female stress urinary incontinence (SUI). They have reaffirmed that retropubic and transobturator slings have slightly different associated complications and that surgeons should educate their patients preoperatively about the potential risks and be prepared to recognize and manage them.

The various types of MUS have been compared extensively ${ }^{1}$ and have also been compared with other SUI procedures in many publications. ${ }^{2}$ In their recent, large metaanalysis, Ford et al ${ }^{1}$ reviewed 81 trials with 12113 woman and concluded that MUS operations have been the most comprehensively researched surgical treatment for SUI in women and have a good safety profile. Irrespective of the route of insertion, they are highly effective in the short- and medium-term, and emerging evidence demonstrates their effectiveness in the long-term. Their review also confirms the positive impact of MUS on quality of life of women with SUI. With the introduction and approval of MUS in the mid to late 1990s, MUS operations steadily increased the overall number of SUI procedures performed and largely replaced traditional procedures, such as the Burch urethropexy, over the next 10 years in North America, where the procedures were tracked. Jonsson Funk et al, using an insurance claims database in the U.S. of 100 payers involving 32.9 million women aged 18-64 years, reported a $27 \%$ increase in the number of SUI procedures from 2000-2009, largely due to a substantial increase in slings, along with a notable decrease in numbers of Burch and other procedures. ${ }^{3}$ Similar increases have been reported by other investigators, ${ }^{4,5}$ and MUS are now termed the gold standard in the surgical treatment of female SUI. ${ }^{6}$

The complication rates associated with MUS also compare favourably with those of other SUI procedures. ${ }^{1}$ In this article, Hengel et al cite a $4 \%$ incidence of patients devel- oping one or more complications within 30 days of their MUS procedure. ${ }^{7,8}$ Novara et $\mathrm{al}^{9}$ reported a rate of $3.2 \%$ for any secondary surgery after MUS in a large meta-analysis. Welk et $\mathrm{al}^{10}$ published the results of a cohort study of 59 887 women who underwent MUS procedures in Ontario from 2002-2012. The cumulative incidence of complications requiring reoperation was 3.29\%.

In October 2008, the U.S. Food and Drug Administration (FDA) issued a public health notification and safety communication due to concern over increased reporting through the Manufacturer and User Device Experience (MAUDE) database of complications associated with transvaginal placement of surgical mesh. ${ }^{11}$ In July 2011, the FDA issued an update on serious complications of transvaginal mesh for prolapse. ${ }^{12}$ Health Canada issued warnings in 2010 and $2014 .{ }^{13}$ While the regulatory authorities clearly stated that the concerns involved mesh for prolapse and not traditional MUS, there was an explosion in litigation for both MUS and prolapse mesh on both sides of the border. Companies have spent billions on legal defense and two companies, Ethicon and Endo (formerly AMS and currently Boston Scientific), ceased their involvement in sling and prolapse mesh product areas due to lawsuit concerns. ${ }^{14}$

Despite the reported complication rate of approximately $4 \%$, the amount of information about mesh in the public media is extensive and does not differentiate between mesh used for prolapse vs. SUI mesh, ${ }^{15}$ but has influenced patients' decisions. In Ontario, the numbers of MUS rose steadily from 2000-2009, but then decreased yearly, along with all other procedures for SUI, until 2012, when they were last tracked. ${ }^{16}$ A similar decrease in the number of SUI operations since 2009 was seen in the U.S. Cantrell et al ${ }^{17}$ analyzed data from 86 academic centres and 1055 surgeons who performed 50315 SUI procedures. They reported a 39\% decrease from 2009-2014. Rac et al ${ }^{6}$ tracked SUI procedures from eight academic institutions with female pelvic medicine and reconstructive surgery specialists from 2007-2013. They reported a non-significant decrease in the use of mesh slings. While the total number of SUI surgeries remained stable, the use of autologous fascia pubovaginal sling increased. 
To try to understand the reasons behind mesh litigation, Zoorob et $\mathrm{al}^{18}$ surveyed 139 women who had undergone mesh-related complication explant at their institution. Of the 95 women who completed the survey, $60 \%$ were involved in litigation. The significant risk factors for pursuing litigation included development of vaginal pain and dyspareunia after mesh placement; persistence of dyspareunia, suprapubic pain, and groin pain after mesh excision; and unsuccessful attempts at conservative management of pelvic pain using pelvic floor rehabilitation. While the investigators did not differentiate between mesh for prolapse vs. SUI, their findings may be helpful in appreciating patient motivation.

On the basis of consistent and widespread published data, professional organizations on both sides of the Atlantic continue to support the use of the multi-incision MUS for SUI. ${ }^{14}$ The Canadian Urological Association position statement is similarly supportive, while underscoring the need for patient education and adequate surgeon training on its proper use and recognition and management of complications. ${ }^{19}$ As surgeons, we should practice on the basis of evidence and guidelines. The additional challenge is to understand the preoperative needs and expectations and to be very sensitive to the postoperative problems identified by the patient sitting before us.

Competing interests: Dr. Herschorn has received grants and personal fees from Allergan, Astellas, Ipsen, and Pfizer.

\section{References}

1. Ford AA, Rogerson L, Cody JD, et al. Midurethral sling operations for stress urinary incontinence in women. Cochrane Database Syst Rev 2015:CD006375. https://doi.org/10.1002/14651858.cd006375.pub3

2. Ogah J, Cody DJ, Rogerson L. Minimally invasive synthetic suburethral sling operations for stress urinary incontinence in women: A short version Cochrane review. Neurourol Urodyn 2011;30:284-91. https://doi.org/10.1002/nau.20980

3. Jonsson Funk M, Levin PJ, Wu JM. Trends in the surgical management of stress urinary incontinence. Obstet Gynecol 2012;119:845-51. https://doi.org/10.1097/A0G.0b013e31824b2e3e

4. Anger JT, Weinberg AE, Albo ME, et al. Trends in surgical management of stress urinary incontinence among female Medicare beneficiaries. Urology 2009;74:283-7. https://doi.org/10.1016/i.urology.2009.02.011
5. Geller EJ, Wu JM. Changing trends in surgery for stress urinary incontinence. Curr Opin Obstet Gynecol 2013;25:404-9. https://doi.org/10.1097/GC0.0b013e3283648cdd

6. Rac $G$, Younger $A$, Clemens JQ, et al. Stress urinary incontinence surgery trends in academic female pelvic medicine and reconstructive surgery urology practice in the setting of the food and drug administration public health notifications. Neurourol Urodyn 2017;36:1155-60. htrps://doi.org/10.1002/nau.23080

7. Cohen AJ, Packiam VT, Nottingham CU, et al. 30-day morbidity and reoperation following midurethral sling: Analysis of 8772 cases using a national prospective database. Urology 2016;95:72-9. https://doi.org/10.1016/i.urology.2016.04.043

8. Slopnick EA, Hijaz AK, Nguyen CT, et al. National surgical trends and perioperative outcomes of midurethral sling placement for stress urinary incontinence. Urology 2017;99:57-61. https://doi.org/10.1016/i. urology.2016.07.027

9. Novara G, Galfano A, Boscolo-Berto R, et al. Complication rates of tension-free midurethral slings in the treatment of female stress urinary incontinence: A systematic review and meta-analysis of randomized, controlled trials comparing tension-free midurethral tapes to other surgical procedures and different devices. Eur Urol 2008:53:288-308. hitps://doi.org/10.1016/i.eururo.2007.10.073

10. Welk B, Al-Hothi H, Winick-Ng J. Removal or revision of vaginal mesh used for the treatment of stress urinary incontinence. JAMA Surg 2015;150:1167-75. https://doi.org/10.1001/jamasurg.2015.2590

11. FDA Public Health Notification: Serious complications associated with transvaginal placement of surgical mesh in repair of pelvic organ prolapse and stress urinary incontinence 2008. Available at https:// wayback.archive-it.org/7993/20170111190506/http://www.fda.gov/MedicalDevices/Safety/ AlertsandNotices/PublichealthNotifications/ucm061976.htm. Accessed May 8, 2017.

12. UPDATE on serious complications associated with transvaginal placement of surgical mesh for pelvic organ prolapse: FDA safety communication 2011. Available at http://www.fda.gov/MedicalDevices/Safety/ AlertsandNotices/ucm262435.htm. Accessed May 8, 2017.

13. Surgical mesh - Complications associated with transvaginal implantation for the treatment of stress urinary incontinence and pelvic organ prolapse - Notice to hospitals 2014. Available at http://www. healthycanadians.gc.ca/recall-alert-rappel-avis/hc-sc/2014/39475a-eng.php. Accessed May 8, 2017.

14. Nager CW. Midurethral slings: Evidence-based medicine vs. the medicolegal system. Am J Obstet Gynecol 2016;214:708 e701-5.

15. Koo K, Gormley EA. Transvaginal mesh in the media following the 2011 US Food and Drug Administration public health notification update. Neurourol Urodyn 2017;36:329-32. https://doi.org/10.1002/ nau. 22923

16. Midurethral slings for stress urinary incontinence. Health Quality Ontario 2012. Available at http://www. hqontario.ca/portals/0/Modals/eds/maps/urinary-incontinence-midurethral-slings-en.html. Accessed May 8, 2017

17. Cantrell AB, Rothschild J, Durbin-Johnson B, et al. Surgical trends in the correction of female stress urinary incontinence in academic centres within the U.S. Neurourol Urodyn 2017;36:394-8. https://doi.org/10.1002/nau.22940

18. Zoorob D, Karram M, Stecher A, et al. Analysis of surgical outcomes and determinants of litigation among women with transvaginal mesh complications. Female Pelvic Med Reconstr Surg 2016;22:404-9. https://doi.org/10.1097/SPV.0000000000000304

19. Welk B, Carlson K, Baverstock R, et al. Canadian Urological Association position statement on the use of transvaginal mesh 2016. Available at http://www.cua.org/themes/web/assets/files/cua_position_statement_on_transvaginal_mesh_v4_np.pdf. Accessed May 8, 2017.

Correspondence: Dr. Sender Herschorn, Division of Urology University of Toronto, Sunnybrook Health Sciences Centre, Toronto, ON, Canada; s.herschorn@utoronto.ca 